\title{
ADUBAÇÃO DA CANA-DE-ACÚCAR: XIV. ADUBAÇẲO NPK EM LATOSSOLO ROXO (')
}

\author{
RAPHAEL ALVAREZ ( $\left.{ }^{2}\right)$, ANTONIO CARLOS PIMENTEL WUTKE ( $\left.{ }^{3}\right)$, HERMANO VAZ \\ DE ARRUDA $\left({ }^{4}\right)$, BERNARDO VAN RAIJ $\left({ }^{5,8}\right)$, ANTONIO CARLOS GOMES $(\hat{)})$ \\ ๑ FREDERICO ZINK ${ }^{7}$ )
}

\begin{abstract}
RESUMO
São apresentados e discutidos os resultados de dezenove ensaios de adubação de cana-de-açúcar, efetuados em latossolo roxo, em diferentes regiōes paulistas. Adotou-se um delineamento fatorial $3^{3}$ para N, $\mathrm{P} \theta \mathrm{K}$, procurando-se avaliar a reaçăo da cultura a esses nutrientes em áreas exploradas havia alguns anos com cana $\theta$ em outras em início de exploraçăo. A variedade utilizada foi a CB 41/76, plantando-se de janeiro a março de 1958. Foram aplicados 0,90 e $180 \mathrm{~kg} / \mathrm{ha}$ de $\mathrm{N} ; 0,80$ e $160 \mathrm{~kg} / \mathrm{ha}$ de $\mathrm{P}_{2} \mathrm{O}_{5} \Theta 0,100$ e 200kg/ha de $\mathrm{K}_{2} \mathrm{O}$. Houve respostas significativas a nitrogênio em dez casos, a fósforo em nove e a potássio em dezesseis. A produção média sem adubo, em todos os ensaios, foi de 82,9t/ha. As doses máximas dos adubos proporcionaram aumentos médios de 15,2t/ha para nitrogênio, de 10,0t/ha para fosforo e de 21,3t/ha para potássio. $O$ ajuste de funçőes de respostas aos resultados permitiu a verificação de que combinações mais econômicas dos nutrientes estão muito acima das recomendações correntes. As respostas da cultura à adubação estiveram diretamente relacionadas com a produtividade máxima económica $\left(r=0,773^{\star *}\right)$. Foi possível identificar relação direta entre respostas a $N$ e produtividade $\left(r=0,695^{* *}\right)$, de respostas a $N$ com o teor de matéria orgânica no solo $\left(r=0,677^{\star *}\right)$ e de fósforo com o teor de $\mathrm{P}$ no solo, determinado pelo método da resina trocadora de íons $(r=$ $\left.0,709^{\star *}\right)$.
\end{abstract}

Termos de Indexação: cana-de-açúcar, adubação NPK, economia, produtividade.

\section{ABSTRACT \\ NPK FERTILIZER EXPERIMENTS OF SUGAR CANE ON DUSKY RED LATOSOL SOILS}

Nineteen $3^{3}$ NPK factorial experiments with sugar cane were carried out in $1958 / 59$ on dusky red latosol soils of various sugar plant owned lands, in the State of São Paulo, Brazil. The amounts of nutrients applied corresponded to: 0,90 and 180

(1) Recebido para publicação em 5 de julho e aceito em 21 de outubro de 1991.

(2) Seçăo de Cana-de-Açúcar, Instituto Agronômico (IAC), Caixa Postal 28, 13001 Campinas, SP.

(3) Seção de Café, IAC.

(4) Seção de Técnica Experimental e Cálculo, IAC.

(5) Seção de Fertilidade do Solo e Nutrição de Plantas, IAC.

(6) Centro de Pesquisa Agropecuária do Cerrado (CEPAC), EMBRAPA.

(7) Usina Junqueira.

(8) Com bolsa de pesquisa do CNPq. 
$\mathrm{kg} / \mathrm{ha}$ of $\mathrm{N} ; 0,80$ and $160 \mathrm{~kg} / \mathrm{ha}$ of $\mathrm{P}_{2} \mathrm{O}_{5} ;$ and $\mathrm{O}, 100$ and $200 \mathrm{~kg} / \mathrm{ha}$ of $\mathrm{K}_{2} \mathrm{O}$. The experiments were separated in two types of areas, based on former soil use: one group in areas where sugar cane was cultivated over ten years, and the other group in areas where which sugar cane had never been cultivated. The results were in accordance with former management, indicating residual effect of phosphorus applications and potassium depletion on the areas former cultivated with sugar cane. However, responses to nitrogen could not be related to former soil usage. Responses of sugar cane to nitrogen were related to soil organic matter $\left(r=0.695^{\star \star}\right)$ and to phosphorus with resin extractable $P\left(r=0.709^{\star *}\right)$, but the response to potassium fertilizer was not related to soil $K(r=0.284 n . s)$. With adjusted response functions, the optimal economical amount of nutrients were shown to be in general, higher than the current recommendations. Yield increases promoted by NPK were directly related to the maximum economic yield $\left(r=0.773^{\star *}\right)$.

Index terms: sugar cane, NPK fertilization, maximum economic yield, productivity.

\section{INTRODUÇÃO}

A alta necessidade em nutrientes da cultura da cana-de-açúcar, decorrente da elevada produção de biomassa por área e da remoção de grande parte dessa massa vegetal no processo da colheita, tem levado a uma revisão periódica das adubações, com alterações para mais, à medida que se esgota a fertilidade natural dos solos ou que se impõe a necessidade ou a conveniência do aproveitamento de áreas de baixa fertilidade natural.

Altas respostas a fósforo foram verificadas em numerosos ensaios de adubação fosfatada, realizados entre 1950 e 1963, com uma média de 26\% de aumento da produção da cana-de-açúcar com a aplicação de superfosfato simples (FREIRE et al., 1968). Contudo, as revisões de ZAMBELLO JR. \& AZEREDO (1983) e de ESPIRONELO (1989b) indicam que o efeito do fósforo não é geral, podendo ser nulo ou reduzido em solos originariamente férteis ou que vêm sendo adubados com fósforo. Assim, MALAVOLTA et al. (1963) constataram efeitos significativos em apenas 4 de 32 ensaios com cana-planta colhidos, enquanto ALVAREZ et al. (1963) observaram efeito de fósforo em 6 ensaios entre os 18 realizados.

Os efeitos do nitrogênio na cultura da cana-de-açúcar tendem a acentuar-se com o tempo de uso do solo (ZAMBELLO JR. \& AZEREDO, 1983; ESPIRONELO, 1989a). MALAVOLTA et al. (1963) observaram efeitos de $\mathrm{N}$ em 10 ensaios dos 32 realizados, enquanto ALVAREZ et al. (1963) constataram efeito significativo em 6 dos 18 ensaios.

Respostas a potássio para a cana-de-açúcar também têm-se acentuado com o tempo (ZAMBELLO JR. \& AZEREDO, 1983; ESPIRONELO, 1989a). Mesmo em dois grupos de ensaios mais antigos, os efeitos de potássio na cana-planta já eram mais freqüentes do que para nitrogênio e fósforo. Assim, a resposta ao potássio foi significativa em 15 dos 32 ensaios relatados por MALAVOLTA et al. (1963) e em 17 dos 18 descritos por ALVAREZ et al. (1963). 
Nos estudos da adubação NPK da cana tem-se adotado, preferencialmente, o delineamento fatorial $3^{3}$, em geral com doses zero e mais duas de cada um dos três nutrientes, num total de 27 combinações. Comumente, a avaliação desses ensaios limitou-se ao uso da análise da variância e ao cálculo aritmético dos efeitos médios dos nutrientes. Desse modo, o potencial dos dados para estimativas quantitativas das adubações não foi suficientemente explorado.

Dando seqüência ao estudo da adubação mineral da cana-de-açúcar nos principais tipos de solo do Estado de São Paulo (ALVAREZ et al., 1963), instalaram-se, em 1958, 25 experimentos em latossolo roxo. Neste trabalho são discutidos os resultados inéditos de 19 deles, dos quais ainda se dispunha de amostras de solo representativas das respectivas áreas experimentais.

Os efeitos dos adubos são expressos por funções de produção $\theta$ as combinações de nutrientes para adubações mais econômicas ou para produções máximas são confrontadas com recomendações correntes. Ao mesmo tempo, é avaliada a possibilidade de discriminar as respostas aos nutrientes estudados pela correlação com os resultados de análise de solo, efetuada segundo o método atualmente adotado pelo Instituto Agronômico (RAIJ et al., 1986)

\section{MATERIAL E MÉTODOS}

Atentando-se para a esperada diversidade de respostas à adubação, de conformidade com o histórico de utilização e de manejo das glebas experimentais - em especial, considerando-se o efeito residual de adubações anteriores - instalaram-se os ensaios em duas situações bem distintas. Escolheram-se, para tanto, um primeiro grupo de áreas não adubadas, nas quais se iniciaria a cultura de cana, e outro de áreas já cultivadas havia mais de dez anos e que recebiam, em cada plantio, uma adubação fosfatada complementada por pequenas quantidades de nitrogênio e potássio.

De acordo com esse critério, os experimentos se distribuiram da seguinte forma (município, usina, número do experimento):

a) áreas não adubadas, nas quais se iniciava a cultura da cana-de-açúcar:

- Jaú, Usina Diamante, experimento $n^{\circ} 1$;

- Ribeirão Preto, Usina Santa Lídia, experimento n: 2;

- Sertãozinho, Usina São Francisco, experimento n. 3;

- Sertãozinho, Usina Santa Elisa, experimentos n. ${ }^{0 s}$ 4, 5 e 6.

b) áreas cultivadas com cana-de-açúcar havia mais de dez anos:

- Jaú, Usina Diamante, experimentos n. 8 e 9;

- Sertãozinho, Usina Santa Elisa, experimentos nos 13, 14, 15, 17 e 19;

- Igarapava, Usina Junqueira, experimentos n.s 20, 21, 22, 23, 24 e 25. 
As principais caracteristicas químicas das amostras compostas dos solos das glebas utilizadas encontram-se no quadro 1. As amostras, coletadas em 1958 e guardadas desde então, foram reanalisadas pelos métodos descritos por RAlJ \& QUAGGIO (1983).

O delineamento experimental utilizado foi um fatorial $3^{3}$ com blocos de 9 parcelas, apresentando confundimento da interação NPK. As quantidades de nutrientes utilizados, em kg/ha, foram de: 0, 90 e 180 de N; 0, 80 e 160 de $\mathrm{P}_{2} \mathrm{O}_{5}$, e 0,100 e 200 de $\mathrm{K}_{2} \mathrm{O}$. Os adubos usados foram o sulfato de amônio, o superfosfato simples e o cloreto de potássio.

A totalidade do fósforo e a metade do potássio foram aplicadas nos sulcos, no plantio; o restante do potássio e metade do nitrogênio, em cobertura, dois meses após o plantio. O restante do nitrogênio foi aplicado aos 8 meses de idade da planta.

As parcelas foram constituídas de cinco linhas de $8 \mathrm{~m}$ de comprimento, espaçadas de $1,40 \mathrm{~m}$. Somente as três linhas centrais de cada parcela foram computadas por ocasião da colheita. As mudas, da variedade CB 41/76, foram colocadas em seqüência ininterrupta nos sulcos de plantio; este foi efetuado no perlodo janeiro-março de 1958 e a colheita, em agosto de 1959.

QUADRO 1. Resultados de análise de solo dos ensaios de cana-de-açúcar

\begin{tabular}{llllllllllll}
\hline $\begin{array}{l}\text { Experi- } \\
\text { mento }\end{array}$ & $P$ & M.O. & $\begin{array}{c}\mathrm{pH} \mathrm{om} \\
\mathrm{CaCl}_{2} \\
0,01 \mathrm{M}\end{array}$ & $\mathrm{K}$ & $\mathrm{Ca}$ & $\mathrm{Mg}$ & $\mathrm{H}+\mathrm{Al}$ & $\mathrm{SB}$ & $\mathrm{CTC}$ & $\mathrm{V}$ \\
\hline
\end{tabular}

\begin{tabular}{|c|c|c|c|c|c|c|c|c|c|c|}
\hline \multirow{3}{*}{$\begin{array}{l}n^{\circ} \\
1 \\
2\end{array}$} & \multicolumn{3}{|c|}{$\mathrm{mg} / \mathrm{dm}^{3} \mathrm{~g} / 100 \mathrm{~cm}^{3}$} & \multicolumn{6}{|c|}{$\mathrm{meq} / 100 \mathrm{~cm}^{3}$} & \multirow{2}{*}{$\begin{array}{l}\% \\
52\end{array}$} \\
\hline & 8 & 3,1 & 5,0 & 0,15 & 3,0 & 1,0 & 3,9 & 4,2 & 8,1 & \\
\hline & 12 & 3,6 & 5,5 & 0,16 & 4,5 & 1,3 & 3,4 & 6,0 & 9,4 & 64 \\
\hline 3 & 6 & 3,5 & 4,2 & 0,09 & 0,4 & 0,1 & 5,8 & 0,6 & 6,4 & 9 \\
\hline 4 & 7 & 4,7 & 5,0 & 0,12 & 4,0 & 1,0 & 5,0 & 5,1 & 10,1 & 50 \\
\hline 5 & 17 & 4,7 & 5,3 & 0,27 & 4,8 & 1,1 & 4,0 & 6,2 & 10,2 & 61 \\
\hline 6 & 11 & 4,2 & 4,8 & 0,12 & 2,0 & 0,5 & 5,6 & 2,6 & 8,2 & 32 \\
\hline 8 & 14 & 2,8 & 5,3 & 0,17 & 2,5 & 1,1 & 3,4 & 3,8 & 7,2 & 53 \\
\hline 9 & 28 & 3,0 & 4,9 & 0,14 & 2,5 & 1,0 & 3,9 & 3,6 & 7,5 & 48 \\
\hline 13 & 49 & 4,3 & 6,0 & 0,11 & 9,1 & 1,3 & 2,4 & 10,5 & 12,9 & 81 \\
\hline 14 & 18 & 5,0 & 5,6 & 0,12 & 6,7 & 1,0 & 3,3 & 7,8 & 11,1 & 70 \\
\hline 15 & 14 & 4,4 & 5,2 & 0,13 & 4,1 & 0,9 & 4,1 & 5,1 & 9,1 & 56 \\
\hline 17 & 14 & 4,1 & 5,1 & 0,10 & 3,0 & 0,7 & 4,3 & 3,8 & 8,1 & 47 \\
\hline 19 & 15 & 3,9 & 5,4 & 0,12 & 5,0 & 0,6 & 3,7 & 5,7 & 9,4 & 61 \\
\hline 20 & 53 & 3,9 & 4,9 & 0,18 & 3,2 & 0,9 & 4,5 & 4,3 & 8,8 & 49 \\
\hline 21 & 36 & 5,6 & 5,6 & 0,16 & 9,0 & 1,8 & 3,8 & 11,0 & 14,8 & 74 \\
\hline 22 & 15 & 4,6 & 5,3 & 0,42 & 7,8 & 1,5 & 4,4 & 9,7 & 14,1 & 69 \\
\hline 23 & 21 & 5,0 & 5,4 & 0,33 & 6,5 & 1,5 & 3,7 & 12,0 & 15,7 & 76 \\
\hline 24 & 21 & 4,3 & 5,1 & 0,28 & 4,3 & 1,2 & 4,5 & 5,8 & 10,3 & 56 \\
\hline 25 & 13 & 4,8 & 5,3 & 0,18 & 5,2 & 1,4 & 3,9 & 6,8 & 10,7 & 64 \\
\hline
\end{tabular}


Além da análise da variância dos dados obtidos, calcularam-se as médias aritméticas dos efeitos dos tratamentos e ajustou-se a função de produção do tipo:

$$
\begin{aligned}
Y=b_{0}+b_{1} N & +b_{2} P+b_{3} K+b_{11} N^{2}+b_{12} N P+b_{22} P^{2}+ \\
& +b_{13} N K+b_{23} P K+b_{33} K^{2}
\end{aligned}
$$

No caso, $\mathrm{N}, \mathrm{P}$ e K representam $\mathrm{kg} / \mathrm{ha}$ de $\mathrm{N}, \mathrm{P}_{2} \mathrm{O}_{5}$ eK $2 \mathrm{O}$, e $\mathrm{Y}$, a produção de cana-de-açúcar, em t/ha.

As funções de produção foram usadas para gerar valores estimados de cana-de-açúcar, para doses atualmente recomendadas para cana-planta em São Paulo (ESPIRONELO, 1985), assim como para a adubação mais económica e para aquela correspondente à produção máxima. No caso das doses atualmente recomendadas, considerou-se o valor médio de $\mathrm{N}$, ou seja, de $80 \mathrm{~kg} / \mathrm{ha}$, em vez de 60 e 100. Nos cálculos das adubações mais econômica e máxima, consideraram-se unidades mínimas de $20 \mathrm{~kg} / \mathrm{ha}$ de cada nutriente e não se ultrapassaram as doses máximas testadas, evitando-se extrapolações, principalmente no intervalo, qualquer que fosse o formato da curva. As combinações de nutrientes, em ambos os casos, foram estabelecidas por cálculos iterativos. Consideraram-se os custos por quilograma de nutrientes, em toneladas de cana. Tais valores foram de 0,080 para $\mathrm{N} ; 0,075$ para $\mathrm{P}_{2} \mathrm{O}_{5}$ e de 0,035 para $\mathrm{K}_{2} \mathrm{O}$, com base em preços vigentes em 1987.

\section{RESULTADOS E DISCUSSÃO}

O quadro 2 apresenta os resultados dos seis ensaios em áreas nas quais se iniciava o cultivo da cana-de-açúcar. Houve efeito significativo a nitrogênio em quatro ensaios, a fósforo em cinco e a potássio em três.

No conjunto dos seis ensaios, os efeitos médios de cada nutriente, em toneladas de cana por hectare, são os seguintes:

$$
\begin{aligned}
& \mathrm{N}, \mathrm{kg} / \mathrm{ha} \quad \text { Cana, t/ha }
\end{aligned}
$$

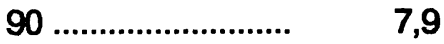

$$
\begin{aligned}
& 180 \ldots \ldots \ldots \ldots \ldots \ldots \ldots \ldots . . . . . . . . . . . .16,6 \\
& \mathrm{P}_{2} \mathrm{O}_{5}, \mathrm{~kg} / \mathrm{ha}
\end{aligned}
$$

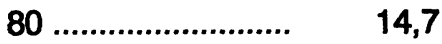

$$
\begin{aligned}
& 160 \ldots \ldots \ldots \ldots \ldots \ldots \ldots \ldots . . . . . . . . . . . . .18,5 \\
& \mathrm{~K}_{2} \mathrm{O}, \mathrm{kg} / \mathrm{ha}
\end{aligned}
$$

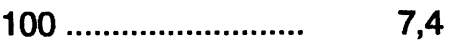

$$
\begin{aligned}
& 200 \ldots \ldots \ldots \ldots \ldots \ldots \ldots \ldots \ldots \ldots \ldots . . . . . . . . .11,1
\end{aligned}
$$


QUADRO 2. Resultados de produção de cana-de-açúcar dos ensaios fatoriais em áreas anteriormente não ocupadas pela cultura, produções médias por dose de nutrientes e resultados da análise da variância

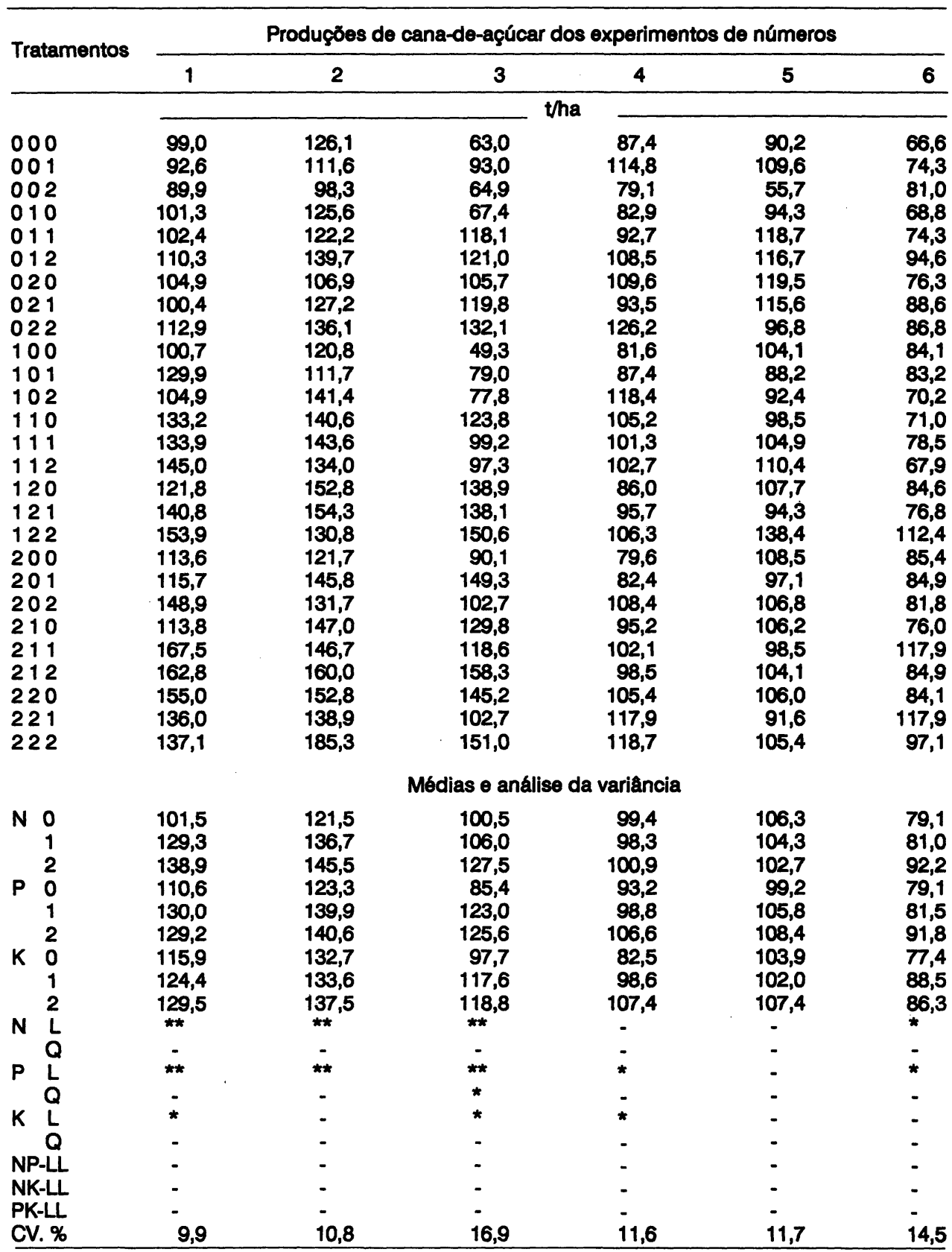


Assim, embora tenha havido reação aos três nutrientes, ela foi mais acentuada para o fósforo, seguido do nitrogênio.

Os resultados dos ensaios em áreas cultivadas havia mais de dez anos (quadros 3 e 4) conduzem a conclusões diferentes. Nos 14 ensaios, observaram-se efeitos similares para o nitrogênio, menores para o fósforo e mais acentuados para o potássio. Os efeitos significativos foram em número de 6 para o nitrogênio, de 4 para o fósforo e de 13 para o potássio. Os resultados médios permitiram computar os seguintes aumentos de produção:

\begin{tabular}{|c|c|}
\hline N, kg/ha & Cana, t/ha \\
\hline 90 & 9,8 \\
\hline 180 & 14,6 \\
\hline \multicolumn{2}{|l|}{$\mathrm{P}_{2} \mathrm{O}_{5}, \mathrm{~kg} / \mathrm{ha}$} \\
\hline 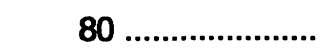 & 4,3 \\
\hline 160 & 6,0 \\
\hline \multicolumn{2}{|l|}{$\mathrm{K}_{2} \mathrm{O}, \mathrm{kg} / \mathrm{ha}$} \\
\hline 100 & 17,4 \\
\hline 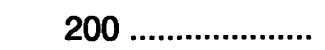 & 25,9 \\
\hline
\end{tabular}

Ressalta o efeito mais acentuado do potássio, em comparação com as médias dos ensaios em que se iniciava a cultura da cana; um efeito menor do fósforo e efeito similar do nitrogênio. Tais respostas se mostram coerentes com o histórico das glebas, refletindo o acúmulo de fósforo pelas adubações anteriores - quase que exclusivamente com esse nutriente - e o esgotamento do potássio, removido em grande quantidade pelas colheitas. O nitrogênio, por originar-se da mineralização da matéria orgânica, tende a tornar-se mais limitante à produção com a exploração continuada da terra. Tal efeito não se comprovou nesses experimentos e no confronto das duas situações focalizadas, seja porque nas áreas nunca cultivadas com cana já se praticassem outras culturas, seja pela possivel ocorrência da conhecida fixação assimbiótica do $\mathrm{N}$ em niveis consideráveis. De qualquer maneira, as informações estão coerentes com as observações de ALVAREZ et al. (1963) sobre um conjunto de 18 ensaios em solo massapé-salmourão; de MALAVOLTA et al. (1963), no relato de 32 ensaios; de ESPIRONELO (1989a,b), na revisão de trabalhos do Instituto Agronômico e, ainda, de ZAMBELLO JR. \& AZEREDO (1983), na revisão de ensaios da região Centro-Sul.

Além da análise da variância, é preciso estabelecer relações quantitativas entre aumentos de produção e quantidade aplicada de nutrientes para a determinação das adubações mais adequadas do ponto de vista econômico. 
QUADRO 3. Resultados de produção de cana-de-açúcar dos ensaios fatoriais em áreas anteriormente ocupadas com a cultura, produções médias por dose de nutrientes e resultados da análise da variância

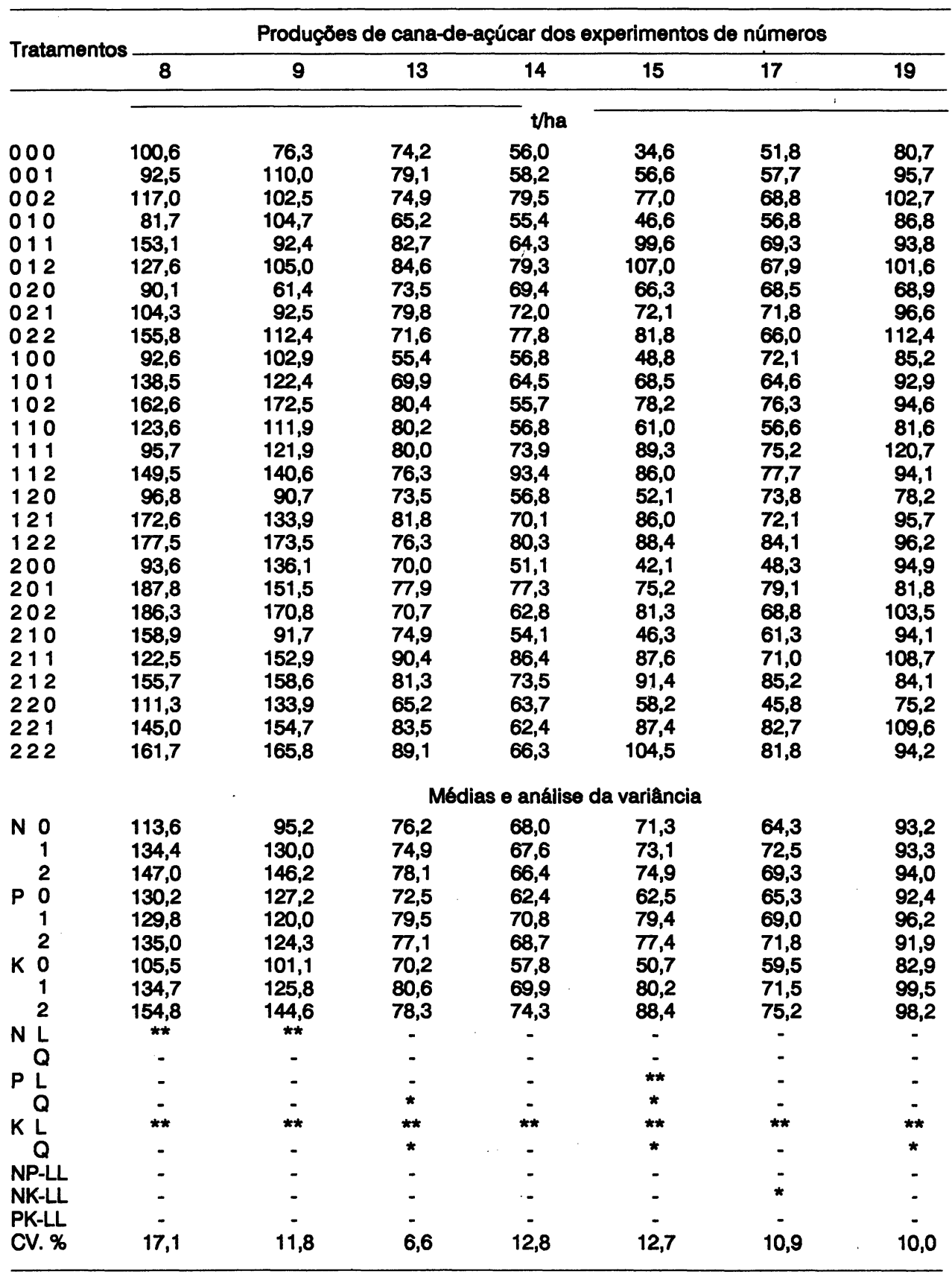


QUADRO 4. Resultados de produção de cana-de-açúcar dos ensaios fatoriais em áreas anteriormente ocupadas com a cultura, produções médias por dose de nutrientes e resultados da análise da variância

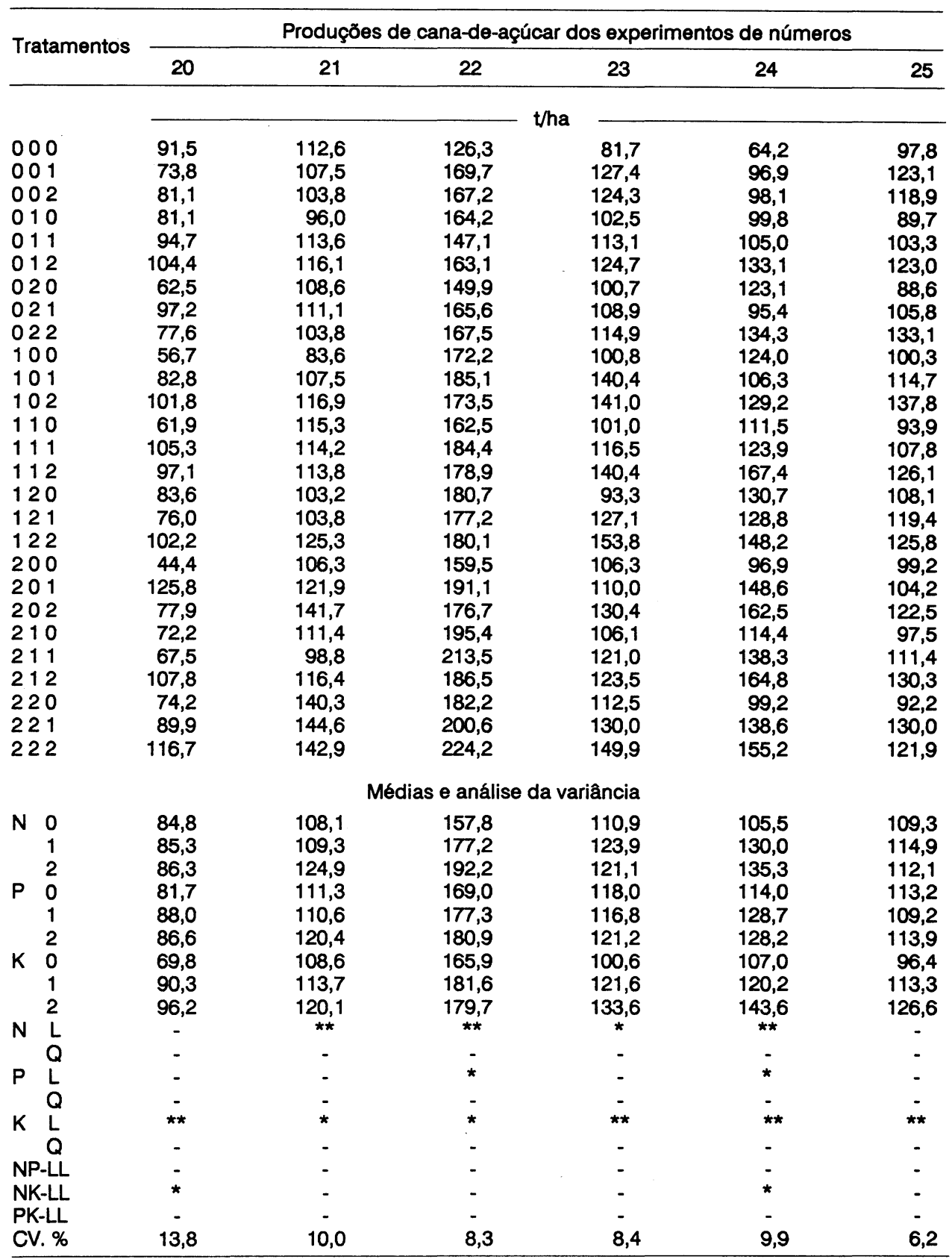


Tem sido comum, em ensaios fatoriais $3^{3}$, o cálculo de médias aritméticas para cada uma das doses aplicadas de cada um dos nutrientes. Os dados dos quadros 2, 3 e 4 resultaram desse procedimento. Tais médias, embora sejam uma estimativa dos efeitos dos nutrientes, são um tanto limitadas para estimativa de produtividade da cana-de-açúcar com vistas à definição das adubações mais adequadas, uma vez que incluem os tratamentos sem aplicação de nutrientes, freqüentemente com baixas produções. Essa ocorrência fol comum também nos ensaios relatados, como o de número 9 , por exemplo, que apresentou média máxima de 146,2t/ha de cana para nitrogênio, ao lado de outros tratamentos com mais de 170t/ha.

Uma abordagem quantitativa mais completa pode ser feita pelo ajuste de funções de resposta. No quadro 5 são apresentados os coeficientes de modelo polinomial do segundo grau, relacionando as produções de cana-de-açúcar com as quantidades de nutrientes aplicadas, ou seja, de $\mathrm{N}, \mathrm{P}_{2} \mathrm{O}_{5}$ e $\mathrm{K}_{2} \mathrm{O}$.

Com os polinômios, é possivel determinar as produções esperadas para qualquer combinação de nutrientes. Três possibilidades foram consideradas neste trabalho: a adubação recomendada; a que permite lucro máximo e a que possibilita produção máxima. No quadro 6 encontram-se as adubações e os aumentos de produção calculados correspondentes.

No cálculo de doses mais econômicas e de produção máxima, observou-se o limite das doses de nutrientes utilizadas nos ensaios. Na maioria dos casos Quadro 6 - a formulação da adubação mais econômica superou bastante a correspondente à recomendação pelos critérios atuais e as diferenças mais marcantes dizem respeito ao potássio. Por outro lado, como era de esperar, a formulação para produção máxima superou as outras duas, mas os aumentos de produção, em média, foram de apenas 5,0 t/ha em confronto com os valores correspondentes da adubação mais econômica.

As adubações mais econômicas não devem ser consideradas incondicionalmente as mais indicadas. $O$ artifício de se considerarem apenas as quantidades múltiplas de 20, empregado nos cálculos, reduz a possibilidade de ocorrência de isoquantas, ou seja, de linhas de mesma produção para diversas combinações de nutrientes. Entretanto, ainda ocorrem valores em doses econômicas que admitem alterações, para mais ou para menos, com muito pouco efeito no resultado final. Desse modo, é importante considerar, também, as necessidades das culturas e levar em conta as tendências médias de conjuntos de ensaios ao estabelecer recomendações de adubação.

Em diversos casos, as doses mais econômicas coincidiram com os máximos testados, significando que os valores reais poderiam ser bem maiores. De qualquer maneira, as informações deste trabalho corroboram aquelas que indicam elevadas necessidades de nutrientes para a cana-de-açúcar (WANM, 1970; ESPIRONELO et al., 1977; CAVALCANTI et al., 1979; REIS \& CABALA-ROSAND, 1986). 


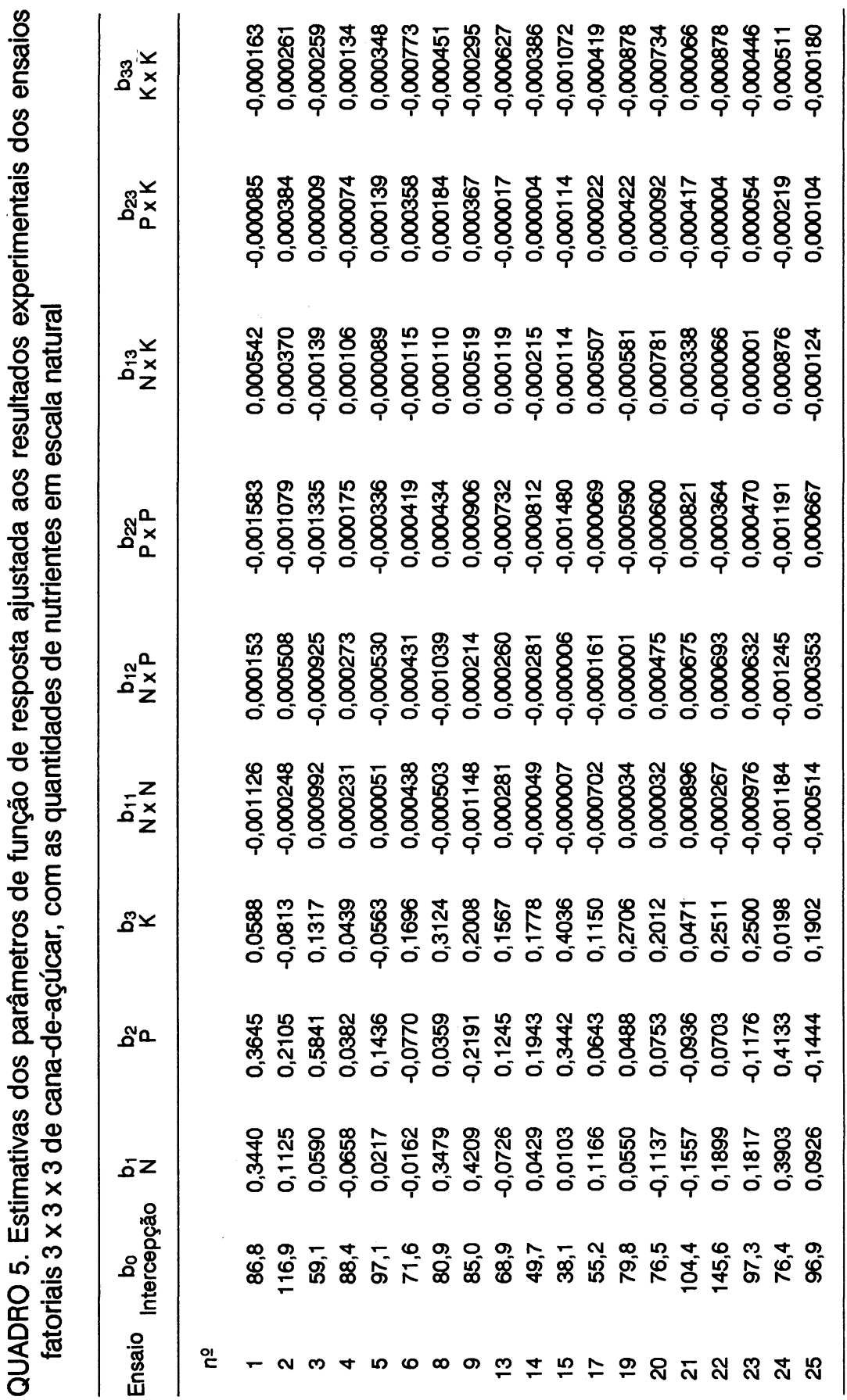




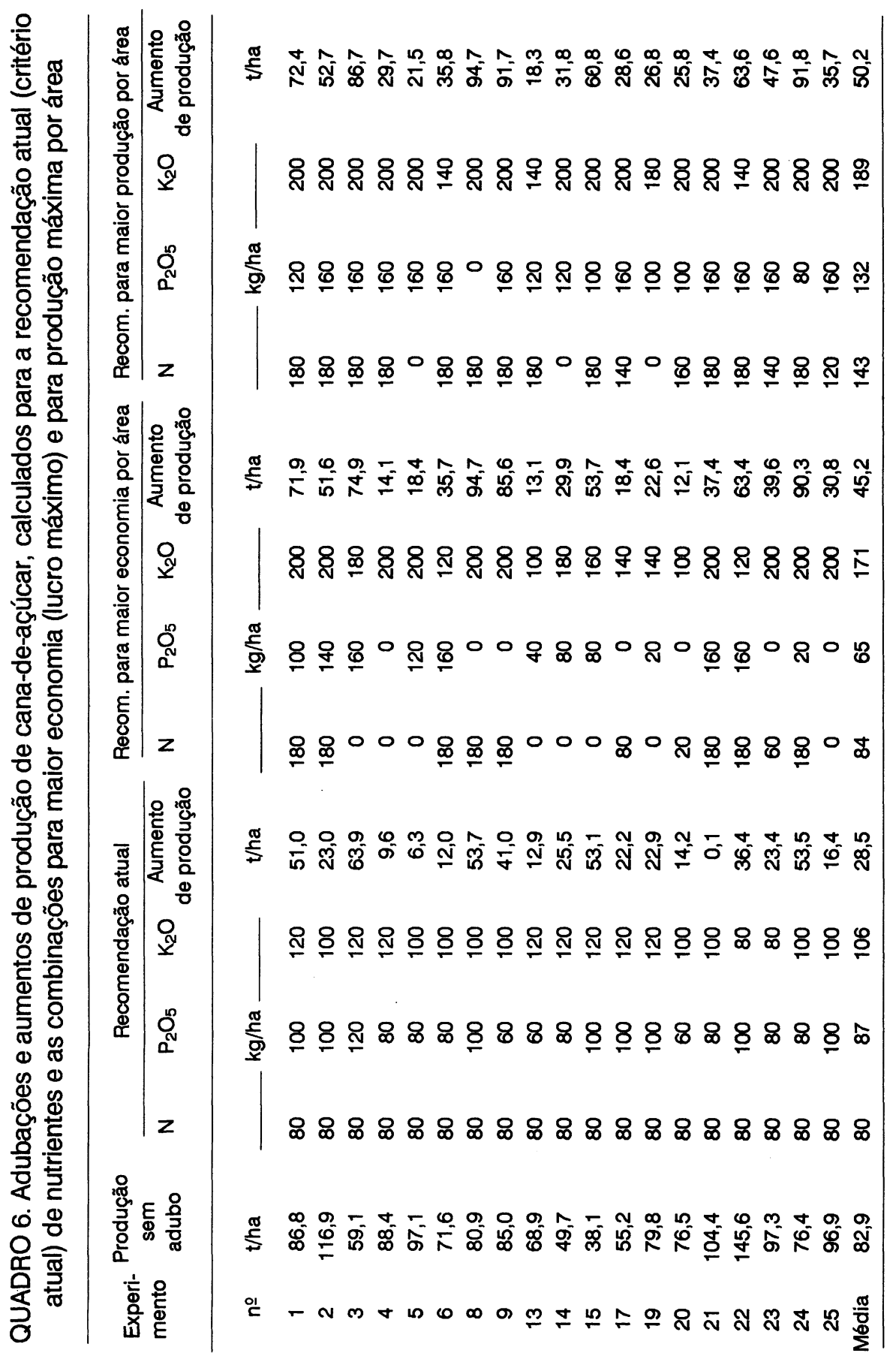


Embora tenha sido testada apenas uma relação custo/valor para nutrientes e cana, os valores usados foram bastante altos, mais de duas vezes superiores àqueles usados por CAVALCANTI et al. (1979). Isso reflete uma situação bem menos favorável da relação de troca do produto pelos insumos. Assim, preços mais favoráveis de fertilizantes deverão levar a doses econômicas ainda mais elevadas do que aquelas mostradas no quadro 6.

Os critérios atuais de recomendação permitem avaliar um aumento médio de produção de 28,5t/ha de cana-de-açúcar, contra 45,2t/ha para a adubação mais econômica e 50,2t/ha para a produção máxima, estabelecidas neste trabalho. A adubação recomendada baseia-se em uma expectativa de produção de 120t/ha de cana-planta (ESPIRONELO, 1985), enquanto pelos cálculos das adubações mais econômicas, as produções variaram de um mínimo de 79,6t/ha no experimento 14 , para um máximo de 209,0t/ha no 22, com um valor médio de 128,0t/ha nos 19 experimentos.

Não é de esperar que uma recomendação visando a uma produção fixa possa ser a melhor alternativa em uma situação de produtividades tão variadas como as verificadas nesses ensaios. Com efeito, foi constatada correlação altamente significativa entre os aumentos de produção observados e as produções obtidas com as adubações mais econômicas - Figura 1. Essa informação indica a necessidade de considerar as produções esperadas nas recomendações de adubação.

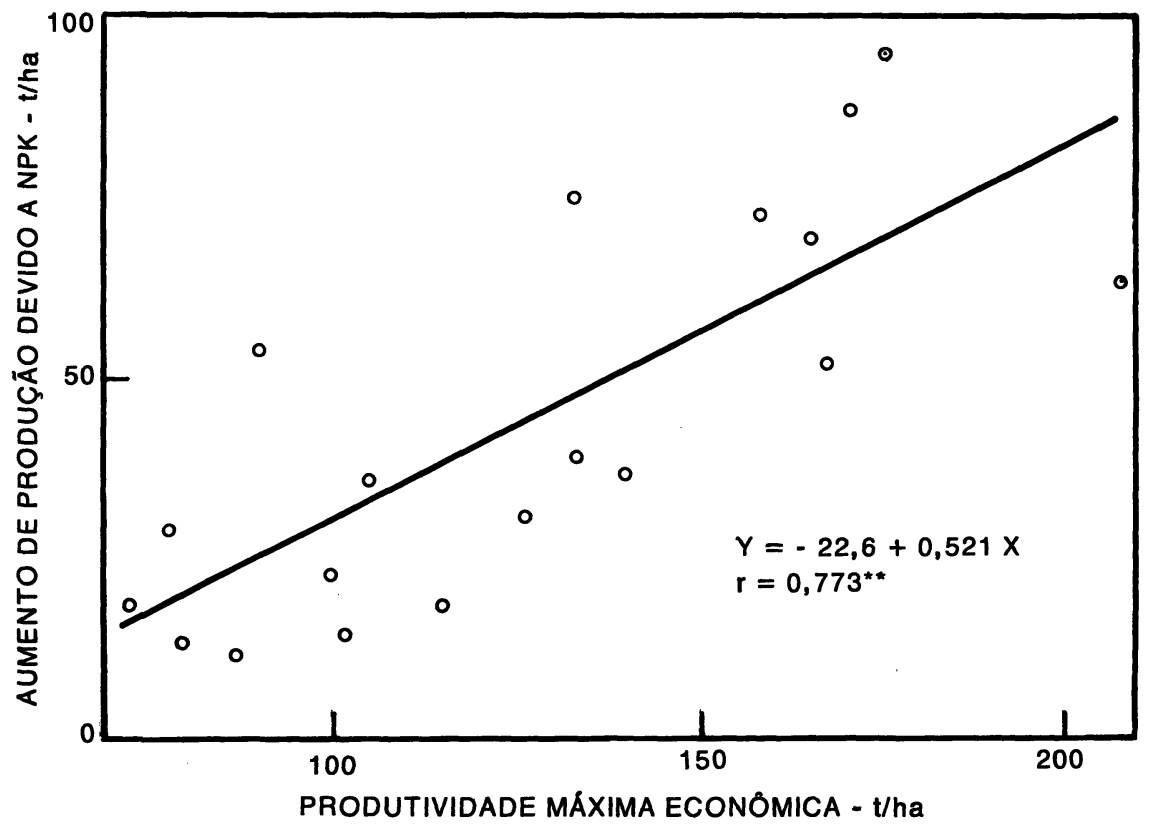

FIGURA 1. Relação entre o aumento de produção de cana-de-açúcar devido à aplicação de nitrogênio, fósforo e potássio e a produtividade máxima econômica da cultura. 


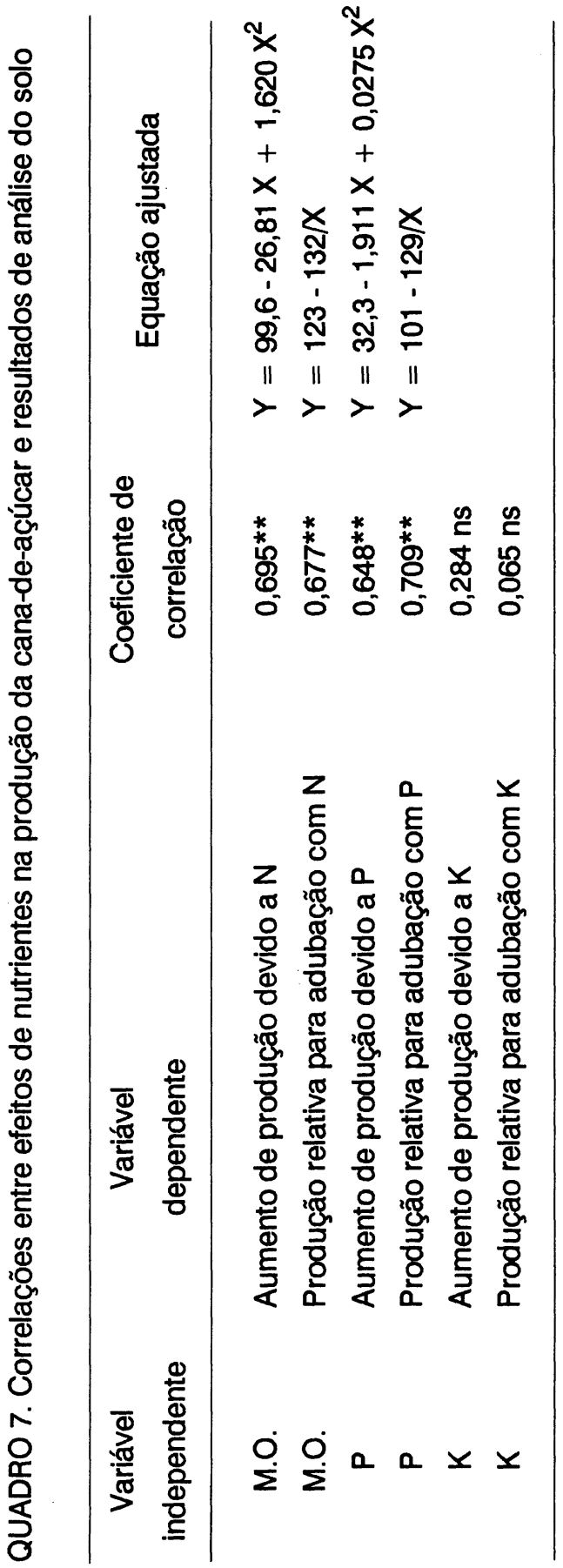


Com base nos aumentos médios - Quadros 2, 3 e 4 - para as doses mais altas de cada um dos três nutrientes, estimaram-se.os seguintes efeitos médios para todos os ensaios:

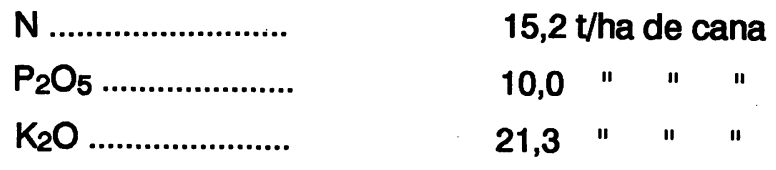

A soma desses valores é de 46,5 t/ha, bastante próxima do aumento de 45,2t/ha, computado para as adubações mais econômicas (Quadro 5).

Embora a adubação recomendada tenha levado em conta a análise de solo para fósforo e potássio, a sua implementação levaria a resultados inferiores àqueles que poderiam ser obtidos na indicação da adubação mais econômica (Quadro 5). Conclui-se, pois, pela conveniência de pesquisas de outras informações que poderiam contribuir para o aprimoramento dessas recomendações.

No quadro 7, as correlações entre resultados de análises de solo e respostas da cana-de-açúcar a cada um dos três nutrientes mostram correlações significativas para matéria orgânica (nitrogênio) e fósforo, mas não para potássio. A correlação para nitrogênio não é comumente observada, mas pode ocorrer quando se reúnem ensaios em uma mesma unidade de solo ou mesmo em solos diferentes, como mostrou a revisão de ANGHINONI (1986) para respostas de feijão, milho, trigo e cevada a nitrogênio e a discriminação dessas respostas pelo teor de matéria orgânica do solo. A correlação das respostas da cana-de-açúcar à adubação fosfatada com os teores de fósforo extraído pela resina trocadora de fons, método especialmente adequado a latossolo roxo, assemelha-se às correlações obtidas com outras culturas (RAIJ et al., 1986). Já a falta de correlação com potássio não encontra explicação, uma vez que é normalmente constatada em cana-de-açúcar e em outras culturas (RAIJ, 1974; ORLANDO F. et al., 1981).

A correlação dos aumentos de produção para as doses máximas de cada nutriente ${ }_{2}$ com a produtividade máxima econômica da cana, mostrou-se altamente significativa para nitrogênio $\left(r=0,841^{* *}\right)$, porém não para fósforo $(r=0,146)$ e potássio $(r=0,261)$. Isso traz algumas dificuldades de interpretação das reações ao potássio, para o qual se esperaria relação semelhante àquela ao nitrogênio, tendo em vista o alto consumo dos dois nutrientes pela cana-de-açúcar.

De qualquer forma, este trabalho indica a necessidade de revisão da tabela de adubação da cana-de-açúcar (ESPIRONELO, 1985), introduzindo o dado de produtividade esperada da cultura e ampliando as recomendações dos três nutrientes.

\section{REFERENCIAS BIBLIOGRÁFICAS}

ALVAREZ, R.; SEGALLA, A.L.; WUTKE, A.C.P. \& FREIRE, E.S. Adubação da cana-de-açúcar: VIII. Adubação mineral em solo massapé-salmourão (1957-58). Bragantla, Campinas, 22:657-675, 1963. 
ANGHINONI, I. Adubaçăo nitrogenada nos Estados do Rio Grande do Sul e Santa Catarina. In: SIMPÓSIO SOBRE ADUBAÇAOO NITROGENADA NO BRASIL, Ilhéus, 1984. Anals. Ilhéus, CEPLAC/SBCS, 1986. p.1-18.

CAVALCANTI, F.J. de A.; FERNANDES, C.S.; GOMES, R.V. \& MOURA, R.J.M. de. Lucro com adubaçăo NPK na cana-de-açúcar em Pernambuco. Revista Braslleira de Clêncla do Solo, Campinas, 3(2):115-120, 1979.

ESPIRONELO, A. Cana-de-açúcar. In: RAIJ, B. van; SILVA, N.M. da; BATAGLIA, O.C.; QUAGGIO, J.A.; HIROCE, R.; CANTARELLA, H.; BELLINAZZI JÚNIOR, R.; DECHEN, A.R. \& TRANI, P.E. Recomendaçōes de adubação e calagem para o Estado de São Paulo. Campinas, Instituto Agronômico, 1985. p.10. (Boletim técnico, 100)

- Contribuição do Instituto Agronômico de Campinas (IAC) para a nutrição e adubaçăo da cana-de-açúcar: I. Calagem, estudos iniciais, nitrogênio e potássio em cana-planta. STAB, Piracicaba, 7(3/4/5):17-28, 1989a.

- Contribuiçăo do Instituto Agronômico de Campinas (IAC) para a nutrição e adubação da cana-de-açúcar: II. Fósforo em cana-planta. STAB, Piracicaba, 8(2):14-21, 1989 b.

; OLIVEIRA, H. de \& NAGAI, V. Efeitos da adubação nitrogenada em cana-de-açúcar (cana-planta) em anos consecutivos de plantio: I. Resultados de 1974/75 e 1975/76. Revista Brasileira de Clêncla do Solo, Campinas, 1 (2/3):76-81, 1977.

FREIRE, E.S.; ALVAREZ, R. \& WUTKE, A.C.P. Adubação da cana-de-açúcar: XIII. Estudo conjunto de experiências com diversos fosfatos realizadas entre 1950 e 1963. Bragantia, Campinas, 27:421436, 1968.

MALAVOLTA, E.; GOMES, F.P.; COURY, T.; ABREU, C.P.; VALSECCHI, O.; HAAG, H.P.; BRASIL SOBRINHO, M.O.C.; MELLO, F.A.F. de; ARZOLLA, J.D.P.; ARZOLLA, S.; RANZANI, G.; KIEHL, E.J.; CROCOMO, O.J.; MENARD, L.N.; NOVAIS, R.F.; FREIRE, O. \& OLIVEIRA, E.R. A dlagnose follar na cana-de-açúcar: IV. Resultados de 40 ensaios fatoriais NPK 3 × 3 × 3, primeiro corte no Estado de São Paulo. Piracicaba, ESALQ/USP, 1963. 47p.

ORLANDO FILHO, J.; ZAMBELLO JÚNIOR, E. \& RODELLA, A.A. Calibração de potássio no solo e recomendaçăo de adubação para cana-de-açúcar. Brasill Açucareiro, Rio de janeiro, 97(1):18-24, 1981.

RAIJ, B. van. Calibraçăo do potássio trocável em solos para feijāo, algodão e cana-de-açúcar. Ciência - Cultura, São Paulo, 26(6):575-579, 1974.

\& QUAGGIO, J.A. Métodos de análise de solo para fins de fertilidade. Campinas, Instituto Agronômico, 1983. 31p. (Boletim técnico, 81)

— - \& SILVA, N.M. da. Extraction of phosphorus, potassium, calcium, and magnesium from soils by an ion-exchange resin procedure. Communications in Soll Sclence and Plant Analysis, New York, 17(5):547-566, 1986.

REIS, E.L. \& CABALA-ROSAND, P. Respostas da cana-de-açúcar ao nitrogênio, fósforo e potássio em solo de tabuleiro do Sul da Bahia. Revista Brasileira de Ciência do Solo, Campinas, 10(2):129 134, 1986.

ZAMBELLO JÚNIOR, E. \& AZEREDO, D.F. de. Adubação na região Centro-Sul. In: ORLANDO FILHO, J., coord. Nutrição e adubação da cana-de-açúcar no Brasil. Piracicaba, IAAPLANALSUCAR, 1983. p.289-313.

WANN, S.S. Experimento com aplicação de diferentes doses dos três elementos NPK nas novas variedades de cana-de-açúcar F 146 e F 148. Fertilité, Paris, (37):3-13, 1970. 